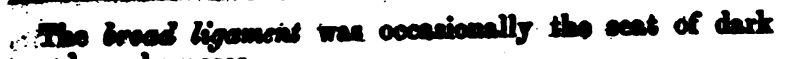

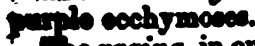

The newo white, opaque, and covered with white curdy flocali, reombling a surface afected with diphtheritic inflammonion.

The Fallopian tubes were more frequently than anj other rat of the uterine system congested and ecchymosed-the slood being frequently extrarasated in the form of zones or ringe. In two cases, gelatiniform cysts were dereloped at their extremities, containing yellow glutinous matter, so rincid as to require considerable force for its extrusion. In the ovaries were frequently found patches of hæmorrhagic extravasation, seated on the surface or in the centre of old corpora lutea. In some cases, they were shrunk, atrophied, and hard; in others, they were the seat of cystic degeneration. The cysts varied in size, in the thickness of their walls, and the colour and consistence of their contents. The largest I saw was the size of a walnut, and contained dark claret-coloured fluid; others were smaller, and contained a gelatiniform mucus.

[To be continued.]

Crichton Rojal Institution, Dumiries, April 1854.

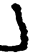

\section{CASE OF HERNIOTOMY.}

By JOHN McINTYRE, M.D.

[Read at the Reading Pathological Society, April 12th, 1854.]

JAMEs CoOpre, aged 67, had been the subject of reducible femoral hernia for some time, but had paid no attention to it, having no idea what it was. It came down occasionally, and usually disappeared on his assuming the horizontal posture.

On Saturday night, December 17th, he slipped up on the ice, but felt no inconvenience from the fall at the time. On Sunday morning, he had pain in his bowels, and romited; and sent to my surgery in the evening for something to ease him. A calomel and opium pill was sent, with an anodyne carminative mixture. These he took; and I saw him on Monday forenoon. He was then quite easy; the abdominal pain and the romiting having disappeared soon after the medicine was taken. He said he had in the left groin a swelling, which I found to be of the size of a small walnut, soft, slightly elastic, free from pain, even on the surface, and occupying the situation of femoral hernia. No appreciable impulse was communicated to it upon coughing. There being no doubt as to its nature, $I$ at once endeavoured to reduce it by the taxis; but, failing to do so, ordered him a pill, containing a grain of opium, every hour. At 10 P. M., he had taken six pills, but was scarcely at all under the influence of the medicine. No pain nor vomiting had recurred; the tumour continued much the same; and he expressed himself as feeling very comfortable. Doubting in some measure whether strangulation now existed, I ordered him some aperient medicine, to be taken at interrals of three hours:i He took two doses, after each of which he romited largely a green mucous fluid; and took no more.

Dec. 20th. In the morning, I saw him, and ordered the opium to be again repeated in doses of one grain every hour. I now discovered that he had only had one grain divided into six pills the previous day, instead of the quantity ordered. It was now giren correctly; and at 7 P.x. he had taken six grains, and was then only slightly narcotised. I did not consider it prudent to wait longer for its action; I therefore at once administered chloroform to full anæsthesia, and gave the taxis a fair and persevering trial for half an hour. It made the tumour slightly smaller, and more relaxed, probably from the displacement of some air; but no reduction sensible to the finger had taken place. As the symptoms were very mild indeed, his pulse being quiet, the abdomen flaccid, and no retching or vomiting being present, I ordered the oplum to be repeated for two hours, and ice to be applied to the tumour. I then

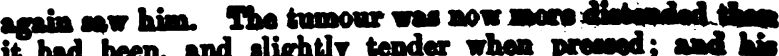
countenance gere evidence of grenter diveomfort. B.in convinced, from the small impresaion that coughing exexte. on the tumour, that the stricture was tight, I deemed it unsafo to try the taxis further, and proposed openating. to which he willingly acceded.

The operation was done in the usual way, by the inverted T incisions. The sac was dark, and contained about a drachm of bloody serum. The stricture was divided in the usual position; but so tight was it, that I had great dififculty in inserting the point of the hernia knife under it. The contents were a knuckle of small intestine, of a pur plish hue, very slightly roughened on the surface from recent fibrinous effusion. On withdrawing it a little; the point of constriction was readily discorered; but no injury to the coats had taken place. On gently replacing the intestine in the abdomen, about four drachms of serum, slightly tinged with blood, were discharged. Not more than three drachms of blood were lost during the operation, and no vessel required ligature. He immediately felt rolieved. The wound was united by two or three points of suture, a compress and bandage applied, and he was placed in bed. The pulse was 70 .

Dec. 21st. He had passed a good night, and felt comofortable. There had been no pain or vomiting. The pulse was 72, moderate in strength, and occasionally intermitting. The tongue was moist and furred; he was rather thirsty. The skin was comfortable. He had passed urine twice. The bowels had not acted. He was ordered to have a large: enems of gruel, and the following mixture :-

B Magnesiæ sulphatis 3 iv.

Sodæ sesquicarhon. $3 \mathbf{j}$.

Aquæ menthæ piperite $\xi \mathrm{rj}$. M.

Fiat mistura, cujus sumantur cochlearia ij ampla 4tis horis.

He was ordered to have broth, gruel, and tea, as food.

8 P. M. He had had a teacupful of broth, and had been eating raw apples. The bowels acted freely three: times from the enema. He bad vomited thrice, and now felt sick. He complained of uneasiness round the upper part of the abdomen, which was rather distended from. fatulence. There was no pain at the wound, or at the: lower part of the abdomen. The skin was hot; the tongue as before. He was still thirsty. The pulse was 72, intermitting at every fourth beat; but no valvular or other heart lesion could be detected by the stethoscope. He was. ordered to take a calomel pill at once, and four drachms of castor oil an hour after.

Dec. 22nd. The oil was rejected about twenty minutes after it was taken, and the nausea and uneasiness continued. I was called to him at four o'clock this morning; on account of vomiting and severe pain at the scrobiculus cordis, the result, I believe, of another dose of the aperient. mixture that had been given to him at 11 P. x. by my assistant. A calomel and opium pill was then given, and ordered to be repeated in two hours. He had in consequence some quiet-sleep, and was, at 10 А. M., free from pain. No romiting had occurred, and the bowels had acted spontaneously at $8 \mathrm{~A}$. M. The pulse was 78; the tongue was moist and somewhat furred. He was rather thirstyHe was ordered a calomel and opium pill every four hours; and ice to suck ad libium.

Dec. 23rd. He had passed a comfortable night. The: borrels had not acted, but he felt that they shortly would. The abdomen was flaccid, and free from pain. The pulse was 90, weak, and still intermittent. I undid the bandage; the round looked well. The pills were omitted.

6 P. x. The bowels had acted four times; the last mon tion was "bloody and slimy". The abdomen was very collapsed; otherwise, he remained in the same state.. The following medicine was prescribed:-

B Tincture opii 3 ss.

Sodæ sesquicarb. $3 \mathbf{j}$.

Mucilaginis $\mathbf{3 j}$.

Aque ऊे. M.

Fiat mistura, cujus capiat cochlearia ij ampla quartis boris. 
2.m aint of gruel, arrow root, and beeftea, hitherto given' ves andared to be continued.

Bec. 84th. The night had been disturbed by repeated actions of the bowels, dysenteric in character, and accompanied with tenesmus. A slight epithelial scale was visible on the gums from the mercury. He was otherwise the ame.

\section{Bo Tincturse opii $\mathbf{3 s s}$}

Decocti amyli 3 viij. Mr.

Fiat enema statim injiciendum.

The mixture was continued.

Evening. The bowels had been quieted since the enema, and he felt better. The opium in mixture was omitted.

Dec. 25th. 10 A. M. He had passed a good night. The bowels had acted once naturally, and without discomfort. The pulse was 76, weak. The tongue was moist and furred; the abdomen was natural. The mixture was continued, with the addition of half a drachm of tincture of opium.

Dec. 26th. He felt better. The bowels had acted twice since last evening, four times since last report. The wound was rather inflamed, the redness extending an inch and a half around. The edges at the angle of the incisions were rather everted, and granulations, healthy in character, were appearing. I removed the sutures, and applied waterdressing. The pulse was 76. The following mixture was ordered :-

\section{R Misturæ cretæ $\mathbf{v j}$.}

Tincturæ opii 3 ss. M.

Fiat mistara cujus sumantur cochlearia ij ampla 6tis horis.

Dec. 28th. He had progressed favourably. A slough had appeared at the bottom of the wound, apparently a portion of the sac; and the discharge was freer than desirable. The bowels were now quite steady, and the pulse was quiet. The edges of the wound were rather flabby, and he expressed himself as feeling weak. He was directed to have a mutton chop and half a pint of porter.

Dec. 29th. He had passed a restless night. The bowels had acted a great many times. The stools were dysenteric in character, and accompanied with tormina; but there was no pain connected with the seat of the operation. The tongue was moist, and cleaner than hitherto. The pulse was 96.

R Pulveris ipecacuanhæ compos. gr. ijss. Confectionis aromaticis q. s. M.

Fiat pilula 4tis horis sumenda.

Bo Sodæ sesquicarb. 9ij

Tincture opii 3 ss.

Misturæ camphoræ $\overline{v j . ~ M . ~}$

Fiat mistura, cujus capiat cochlearia ij ampla tis horis.

Dec. 30th. 10 A.M. He had passed a very restless night, the bowels having been moved nine times. The stools were dysenteric, and apparently mixed with pus. The pulse was 72. The tongue was clean and moist. The edges of the wound looked well. The slough had almost entirely separated. The discharge was freer than desirable. On pressing the left iliac region, two or three bubbles of air passed through the wound, showing that the communication with the peritoneum was not obliterated.

B Tincturæ opii 3 ss. Decocti amyli zviij. M.

Fiat enema statim injiciendum.

B Misturæ cretæ 3 vj.

Tincturæ opii mex

Confectionis aromaticæ $\ni$ ij. M.

Fiat mistura, cujus capiat cochlearia ij quaitis horis.

Evening. The bowels had acted three times; the stools were feculent, and mixed with blood and mucus. He had no pain, and felt comfortable. The enema was repeated.

Dec. 31st. The bowels had not been moved. He felt more comfortable in every respect. The slough was entirely separated; the discharge was much less; and the granulations were healthy.

The reports from this date tell of his gradual recovery ; all that he required being a little oil occasionally to reguhate the bowels. The cicatrix is now hard, contracted, and depresced; and, although he is at present following his usual occupation of a carpenter, without a truss, not the slightest protrusion has occurred.

hrusars. One point worthy of observation in the case is the non-urgency of the symptoms, local and general, whilst the constriction was so tight; showing clearly, that to wait for the supervention of severe symptoms as a justification of operative interference, when the taxis has failed and undoubted evidence of obstruction exists, is a practice at once unsound and reprehensible. No application of the taxis in this case, with all the juvantia to boot, could ever have effected the reduction; and I believe that we shall always, under such circumstances, best consult the welfare of our patient, the credit of the operation, and our own reputation, by having immediate recourse to the knife.

What constituted the slough? Although it be an unusual thing for sacz to slough, still I believe that such was the case here. The depth of it ; the apparent non-closure of the peritoneal cavity at a late period, as evidenced by the air expelled from the wound upon pressure of the iliac region; the contracted character, firmness, and depression of the cicatrix; and the apparent radical cure, are in favour of this view.

What caused the sac to slough? In other cases of femoral hernia, upon which I have operated successfully, no such result has followed, although the operations were precisely similar. In these cases, moreover, firm adhesions had to be destroyed betwixt the sac and the contained omentum, thus favouring the occurrence of the death of tissue. As the sac did not slough in these cases, I am, I think, justified in concluding that the sloughing in that before us was independent of the operation, -i.e., indopendent of the manner in which it was performed. That it was not dependent on the application of ice is evident, from no injury to the integuments having followed the use of this means; and from the fact of the sac deriving its nourishment from a source other than the common femoral, and more beyond the influence of cold. The pressure to which the sac was subjected during the application of the taxis, although no rude handling was practised, might have aided in the production of the slough; and the slight ptyalism, to which the patient was accidentally subjected, also; but the true cause will be found, I believe, in the: stangulation of the sac itself, as shown by its lividity, and the unusual tightness of the stricture.

The muco-enteritis, I belicve, arose from a combination of causes: from the use of the aperients; from the specific action which mercury has upon the bowels of some individuals on its introduction, howerer slightly, into the system; possibly from ulcerative action having taken place in the constricted portion of mucous membrane, and from errors in diet. The second attack seemed distinctly connected with the mutton-chop and porter; but that they alone were to blame for its production, I very much doubt;: for oranges, figs, raisins, plum-cakes, et hoc genus omne, although the strictest injunctions were laid upon him as to. diet, were frequently taken from under the bedclothes.

The markedly beneficial influence of the opium throughout the case especially deserves notice; adding as it does to the evidence in favour of its use in strangulated hernia, and in abdominal injuries and diseases generally. That an almost inconceivable amount of relaxation of fibre may be obtained through its use, I have several times fully ascertained; and $I$ know of no remedy that is for a moment to be placed in comparison with it as an adjuvant to the taxis. I have now on two other occasions had recourse to chloroform as a substitute, and have administered it fully; but, although the reduction of the hernia has been effected, the general relaxation of the system has not been so great. I should therefore be more disposed to trust to the opium, though slower in action-especially in cases of inguinal hernia, where the structures implicated are more yielding than to its more ready and modern rival.

Most recent writers, in the after treatment of cases of hemiotomy, advocate the propriety of conceding rest to the bowel to enable it to recover the injury which its atructure or function may hare sustained; and this, not only by 
Aneining from the uw of aperients, but by administerin wing to accomplish it. The duration of this ropose wil 7ar of course with individinal cases; but authorities wy, tint some hours in all should be allowed to elapes before crients are administered. The quantity of opium will A. vary with the case, and will depend upon whether the mitient has been brought under its influence during the tivil of the taxis. In the present case, the patient continued drowsy after the operation was completed, and none wo given until the bowels were relieved. Mr. Guthrie recommends that one grain should be given two or three times a day, according to its effect, for the first two days, and be followed up by a large emollient enema at the expiration of that time. I confess that I was not sufficiently delivered from the trammels with which the long inculcated orthodoxy of the aperient treatment had entwined me, to wait so long; but when the vomiting and pain that occurred on their administration supervened on a hitherto farourable condition, I repented of $\mathrm{my}$ adherence to past teaching, and resolved, in future crses, to adopt that plan unhesitatingly, which modern science has shown to be the most rational, and modern experience the most successful treatment.

But, it may be asked, why resort to the old operation of opening the sac, when a less hazardous -in most cases equally effectual, and when so, in all more successful-operation can be performed; viz., that devised by Mr. Gay? My reason aimply was, that I had no knife which I thought properly adapted for it. The difficulty-what there is - of the operation appears to me to consist in introducing the point of the knife betwixt the sac and Gimbernat's ligament; and if its beak is not properly fitted for its work, of course the difficulty to the operator and danger to the patient will be increased. I, howerer, before opening the sac, satisfied myself of the comparative ease with which Mr. Gay's operation may be accomplished; and, when cases present themselves, shall certainly avail myself of it. Its simplicity, and comparative freedom from dangerous results, will induce many to resort to it earlier, and with less compunction, than to the old operation, respecting the fatality of which one has read and heard so much. Not that I share in the fears entertained by some of the operation for hernia, on account of the large mortality that attends it ; for, from my own, certainly very limited, experience, I by no means consider it the fatal operation that some do, believing that the fatality arises, not from the operation per se, but from its not being performed when a fair chance of recovery exists; viz., before the supervention of inflammation and its consequences. I verily believe, if the stricture were immediately liberated by the knife, when a fair trial of the taxis by one accustomed to its application has failed, and no repeated trials by different individuals were allowed, we should find the operation to be much more successful, and the gloom that seems to hang over some minds in connexion with it would be greatly and speedily dispelled.

Odiham, Hants, April, 1854.

\section{BIBLIOGRAPHICAL NOTICES.}

Chimical Lectures on Paralysis, Digeage of the Brain, aNd other Apfections of the Nervods Ststem. By Robert Bextlex TODd, M.D., F.R.S. pp. 462 . London: 1854.

Thess instructive Lectures on cerebral diseases weredelivered by Dr. TODD on various occasions during the last ten years, and are now published in a collected form "at the expressed desire of a large number of those, to whom they were addressed". Their sterling merit amply justifies the author in responding to the call thus made.

The subjects treated of are, various forms of Paralysis (in Ioctures I to XVI inclusive); Syphilitic Disense of the Dura Iater (in Lecture xvII); Trismus and Tetanus (in Lecture

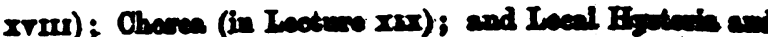
Catalopes (in Incture xx).

As, from the lectures having been given from tim to than on such cases as requirod illustention, the sume subject is often treated of in various parts of the work, we purpons instead of analysing each lecture separately, to make $a$ for selections from the author's remarks, as they can be collected from the various passages in which they occus.

Paralysis froy Digeagy or The Brary. In the various lectures which treat of this subject, we meet with many instructive remarks. In one of the cases (Thomas Hardwick, aged 40, lectures II and III), there was fixed pain in the left side of the heed; paralysis on the opposite side to that of the pain-the paralysis having been preceded by convulsive movements, and being incomplete and accompanied by rigidity of the muscles; and irregular movements of the eyeballs and double vision. These circumstances led Dr. Todd to make the following diagnosis :

"The lesion is of an inflammatory kind, and is principally and primarily meningeal. So far I can speak without hesitation; but in determining the precise locality more difficulty is experienced. I have no doubt, however, that it is so situated as to affect the optic and third pair of nerves; and, from the seat of the pain, which the man has always referred to the left parietal bone, and should assign as its locality the dura mater, and the other membranes in the vicinity of the anterior and inferior angle of that bone; thence the disease has extended perhaps along the fissure of Sylrius, and thus it has come to involve the optic and third pair of nerves. It must be obvious, however, that the disease night readily have set up first in the pia mater, and may have involved the origin of the uerres through some other parts of the brain, producing precisely the same train of symptoms." (pp. 35-6.)

The post mortem examination of the case showed the dure mater to be healthy; and further showed an error in the diagnosis, in not having indicated the optic thalamus as the part of the brain secondarily affected. The idea of the seat of the disease was also erroneous. The diagnosis was, however, correct so far as it stuted the disease to be on the left side of the brain, to be seated in the meninges, and to be inflammatory.

On certain points in connexion with this case, Dr. Todd makes some remarks which cannot fail to increase confidence in him as a careful observer and an honest teacher.

Valle of Firror in Dingnosis. "It is a duty we owe ourselves to scrutinise particulurly any errors we commit, either in dingnosis or in prnctice. Depend upon it, if you do this faithfully, you will derive great benefit from it; your experience will be intinitely more profitable than if you slur over your mistakes without explanation or inquiry. On this account, I make it a rule never to pass by any mistake made here in diagnosis or practice; and I feel that, in commenting upon such to you, I am far more likely to benefit both you and myself, than were I to dilate at length upon successful cases. The successful cases speak for themselves; the failures we would fain throw a veil over; but be assured, in so doing, we benefit neither science nor ourselves.

"A diagnosis may be erroneous in two ways; the one, in which it is absolutely incorrect; the other, where the principles upon which the diagnosis is conducted are sound, and have not been violated, but still the detail s of the diagnosis may not be absolutely correct. 'The first of these is likely to happen when an examination of the patient's condition has not been sufficiently careful; or where the information supplied to us has been incomplete or inaccurate; but the second may occur from the absence of symptoms of a sufficiently distinctive character to give us the precise information we require, or where the attention has been unduly occupied by the inordinato development of some particular symptom." (pp. 46-7.)

The error in the case referred to was caused partly by the difficulty of determining the precise locality of lesions in brain disease, and partly by the prominence and very local character of the pain.

Condition of the Múscles in Paralyged Irmbs. In connexion with the case above referred to, Dr. Todd made some remarks on this subject, which will be found at pages 32-34 of his work: and he again comments. on it in a subivquent Lecture (Ix) from which we must male a quotation. 